\title{
New technologies in the health sector
}

\begin{abstract}
Information and communication technologies are getting health systems to modify their assistance models to offer care oriented towards a more personalized, predictive, preventive and participatory health care. But the process is complex and its implementation requires great efforts, but also involves new possibilities for professionals, patients and health institutions. Knowing how to use them and knowing the advantages obtained through their use, will reinforce the professional practice and increase the acquired knowledge, which will be a great benefit for all the actors involved in the health process.
\end{abstract}

Volume 3 Issue 3 - 2017

\author{
Maria Isabel Arandojo \\ Nurse of the Medical Service of the Young Guard College \\ "Duque de Ahumada" of the Civil Guard, Spain
}

Correspondence: Maria Isabel Arandojo, Nurse of the Medical Service of the Young Guard College "Duque de Ahumada" of the Civil Guard, Spain, Email maribelarandojo@gmail.com

Received: June 07, 2017 | Published: July 12, 2017

\section{Introduction}

For more than two generations, Information and Communication Technologies (ICT) have been an indisputable change factor in the health sector. They represent a great challenge to which health systems have to face and, besides, they are the only tool that allows to approach to the change of what is known as "P4 Medicine" (personalized, predictive, preventive and participatory) and ${ }^{1}$ to modify the care model: From essentially face-to-face healthcare to ubiquitous care, combining face-to-face and remote patient management. From a reactive medicine, based on waiting until the appearance of symptoms to start the healing work, towards a more continuous medicine focused on prevention and health promotion. From an assistance centered on observation of the patient to quantification. From health care that generates a large amount of unstructured data for storage, to the intelligent organization and exploitation of such data. From disconnected and fragmented care to connected and integrated care, patient-centered rather than disease or care processes. From a receptive and reactive attitude on the part of the patient, to be a person who actively seeks health information, is kept informed and is responsible for their self-care. The use of ICT was originally aimed at optimizing processes, increasing productivity and financial management, in what is known as the era of "hospital information systems". However, in understanding the workflow and clinical context as a series of complex processes in which the patient and his /her interaction with the health system are the center of the scene, these systems evolved towards "health information systems", where the capture, exchange, storage, access and management of clinical information are fundamental to contribute to the quality and efficiency of health care, accessibility to its services and medical knowledge. Then health informatics emerges as a discipline that seeks to develop and to manage efficiently these new health information systems. ${ }^{2}$

ICT is already used in so many and different ways in the field of health care that there is no aspect or service that is out of its influence: from health planning and modernization of hospitals for reaching authentic hospitals 2.0 , to electronic medical history, tele-assistance and electronic pre-appointment, considering the management of security systems and the protection of citizens' data. So much ${ }^{3}$ so, that the new term "eHealth" has emerged to refer to the application of ICT, especially in the Internet, in the field of health, driven by the information and communication technologies industry and its marketing departments, in the context of the proliferation of the " $\mathrm{e}$ " in many activities related to electronic commerce. ${ }^{4}$
Technology, in turn, becomes the eyes and ears of science. Without going any further, the computer has contributed to make very important progress in the investigation of complex systems whose study would otherwise have been almost impossible, such as the genetic map. Technology is vital for scientific purposes of measurement, data collection, sample collection and processing, calculations, protection of hazardous substances and communication, among other things, and produces more and better instruments and techniques that enable the accelerated progress of the diverse lines of scientific activity. ${ }^{5}$

Equally evident is the potential of ICT applications in narrowing geographical gaps, facilitating the access to resources, diagnostics or knowledge of scant specialists through the interconnection of health centers of different levels and not only from an urban-rural dichotomy, but also between cities and towns of different sizes. In the same way, with the sustained aging of the population, the applications of televigilance acquire more and more relevance for the control of chronic patients, thus increasing the quality of care. ${ }^{6}$ ICT is the opportunity to foster changes in the management of clinical processes and, with it, to increase the efficiency and the improvement of the clinical results and the sustainability of the system.

\section{Discussion}

The implementation of ICTs in health systems is a complex process, which requires considerable effort and represents a major challenge, but also presents a range of possibilities for health institutions and systems. This process can be analyzed from three different aspects:?

1. Perspective of nursing professionals.

2. Perspective of patients.

3. Perspective of the health system.

\section{Perspective of nursing professionals}

The new technological scenario involves attending to users who have all their health information and have access to it in a continuous and unlimited, which generates new demands for the system and its professionals in general and for nurses in particular. This highlights the need for health personnel to be trained in the use and critical knowledge of ICT tools to respond to the patients' new demands, who are more informed and more knowledgeable on their health. The care is more personalized and time management needs to be better, to which ICT contribute by reducing the dedication to administrative 
processes and providing greater continuity of care among the levels involved in care.

\section{Perspective of patients}

Citizens are at the center of the system and play an active role, in front of the passive vision of yesteryear. This means that they must assume a change of role in their relationship with the health system, because they are co-responsible for everything related to their health and their illness.

Patients demand more information about any topic related to their health or that of their relatives and participate in the planning of care. When health information is readily available, users can make informed decisions about their health, which improves care management, as well as avoid duplication of tests and medical errors. ${ }^{8}$ It is primarily the younger population that usually accesses and uses these resources, which allow them at any time and in any place to consult explorations and clinical information in general, eliminating unnecessary travel and waiting and providing comfort to the care process, so the advantages for the patient in an ICT-based environment are evident.

Health administrations are developing tools for patients to access their health information. They are health channels or portals, based on the Internet, which allow the citizen to access information, perform procedures, receive information and alerts, participate in virtual communities and create their own content, which responds to the demand for more transparency and more ability to choose and participate in decision-making.

\section{Perspective of the health system}

There is an obligation to adopt profound changes in the organization of health institutions due to the significant increase in expenditure, the reduction of available resources and the need to increase organizational efficiency, and the technological environment brings great possibilities and opportunities for improvement. The high initial cost of the unstoppable implantation of the technology in the sanitary systems and the training effort that it supposes, is a great challenge for the system and its managers.

\section{Conclusion}

The application of technique and technology in the health sector, and specifically in nursing, is a starting point for increasing professional quality, providing more specific care, solving different situations more efficiently and contributing to the welfare of man and the maintenance of life. The technology applied to human care offers methods and techniques that strengthen the practice, so its use is necessary, but however elementary it may be, it must be known how to use and understand their applications so that it becomes part of the care process and do nursing work more efficient. This is the challenge of Nursing in the 21st century. If the advantages that can be used in daily practice are known, it will strengthen the professional practice and increase the knowledge acquired, which will be a great benefit for Nursing, for users of the health system, for health institutions and for the new generations of nurses to come.

\section{Acknowledgements}

None.

\section{Conflict of interest}

The author declares no conflict of interest.

\section{References}

1. Martínez Ruiz I, Martínez Salgado M, Alberich Bayarri Á, et al. Tendencias a future Bit. 2013;195:64-67.

2. Plazzotta F, Luna D, González Bernaldo de Quirós F. Sistemas de información en salud: Integrando datos clínicos en diferentes escenarios y usuarios. Rev Peru Med Exp Salud Publica. 2015;32(2):343-351.

3. Arandojo Morales MI. Nuevas tecnologías y nuevos retos para el profesional de Enfermería. Index Enferm. 2016;25(1-2):38-41.

4. Traver Salcedo V. El ePaciente y las redes sociales: ITACA-TSB; 2011.

5. Jaramillo LJ. Ciencia, tecnología y desarrollo. En: Cartillas para el Docente ICESI; No14. Santiago de Cali: Universidad Icesi; 2011.

6. Fernández A. TIC y salud: promesas y desafíos para la inclusión social Newsletter: Salud y TIC; 2010.

7. Galimany Masclans J, Roca Roger M, Girbau García MR. Las tecnologías de la información y la comunicación en los sistemas sanitarios. Un nuevo reto para la enfermera. Metas de Enfermería. 2012;15(3):6-10.

8. Pushpangadan S, Seckman C. Consumer perspective on personal health records: A review of the literature. OJNI. 2015;19(1). 